\title{
Motor Nucleus of the Trigeminal Nerve
}

National Cancer Institute

\section{Source}

National Cancer Institute. Motor Nucleus of the Trigeminal Nerve. NCI Thesaurus. Code C33140.

An aggregation of $\mathrm{CN} V$ cell bodies located in the mid-pons at the level of attachment of the trigeminal nerve to the brainstem; it is the origin of special visceral efferent (motor) fibers that innervate the muscles of mastication. 